\title{
Rupture of a seismic gap in southeastern Alaska: the 1972 Sitka earthquake $\left(M_{\mathrm{s}}\right.$ 7.6)
}

\author{
Melissa M. Schell and Larry J. Ruff \\ Department of Geological Sciences, University of Michigan, Ann Arbor, MI 48109 (U.S.A.)
}

(Received August 20, 1987; revision accepted February 16, 1988)

Schell, M.M. and Ruff, L.J., 1989. Rupture of a seismic gap in southeastern Alaska: the 1972 Sitka earthquake $\left(M_{\mathrm{s}}\right.$ 7.6). Phys. Earth Planet. Inter., 54: 241-257.

\begin{abstract}
The Sitka, Alaska, earthquake of July $30,1972\left(M_{2}=7.6\right)$ is one of the largest strike-slip events since 1963. This earthquake is thought to have ruptured the Pacific-North America plate boundary segment between the large strike-slip events in 1949 and 1958, and the Sitka earthquake was heralded as one of the first successful 'forecasts' of an earthquake based on the seismic gap hypothesis. Another motivation to study this event is the availability of a strong-ground motion recording $\sim 50 \mathrm{~km}$ from the epicenter, which is near the middle of the $180 \mathrm{~km}$ long plate boundary segment. The teleseismically located aftershocks occur only in the southern half of this segment. We have analyzed Rayleigh waves and P waves recorded by WWSSN long-period vertical instruments. A total of 25 very-long-period Rayleigh phases (R2-R5) define a symmetric four-lobed radiation pattern from which we can infer a nearly pure right-lateral strike-slip fault, striking $340^{\circ}\left(\mathrm{N} 20^{\circ} \mathrm{W}\right.$ ), and a bilateral rupture. Comparison of synthetic and observed Rayleigh waves yields a seismic moment of $3 \times 10^{27} \mathrm{dyn} \mathrm{cm}\left(M_{\mathrm{w}}=7.6\right)$. The $\mathrm{P}$ waves are characterized by a dominant complex pulse in the first $40 \mathrm{~s}$, and a succession of smaller pulses after that. The source time functions are deconvolved from $32 \mathrm{P}$ waves with good azimuthal distribution to obtain the moment, depth extent, and rupture history. The mean moment of the source time functions is $5.0 \pm 2.4 \times 10^{27} \mathrm{dyn} \mathrm{cm}$, and the depth extent is 0-10 $\mathrm{km}$. Tomographic inversion of the source time functions produces an image of the earthquake rupture process. This procedure maps the moment release of the complex pulse into two high-displacement regions (i.e., asperities): (1) the epicentral area to $40 \mathrm{~km}$ north, and (2) between 60 and $90 \mathrm{~km}$ south of the epicenter. The main asperity just north of the epicenter coincides with a quiescent zone of microaftershocks. While the overall average seismic displacement is 6 $\mathrm{m}$, the displacement at the main asperity is $7 \mathrm{~m}$, the same value as the tectonic displacement accumulated since the previous earthquake in 1848. The fault averaged stress drop is 100 bars, while the asperity stress drop is 130 bars. Tomographic imaging of the source time functions thus resolves several features of the rupture process, notably the bilateral propagation and rupture initiation at the largest asperity. This is in contrast to the large 1976 Guatemala strike-slip earthquake, where the largest displacements occurred away from rupture initiation.
\end{abstract}

\section{Introduction}

Plate motion at many underthrusting and strike-slip boundaries occurs through the somewhat regular occurrence of large earthquakes $\left(M_{\mathrm{S}}\right.$ $\geq 7.5$ ). Observations of this behavior led to the seismic gap hypothesis (Fedotov, 1965; Mogi, 1969; Sykes, 1971; Kelleher et al., 1974; McCann et al., 1980), which provides a framework for long-term earthquake forecasting. Several success- ful 'forecasts' have now occurred in subduction zones, and one successful 'forecast' in a strike-slip environment was the 1972 Sitka earthquake. It is important to understand the rupture process of earthquakes that occur in these seismic gaps, not only to determine whether the entire gap was ruptured, but also to understand where and why large earthquakes occur.

The Pacific-North America plate boundary motion changes from underthrusting along the 


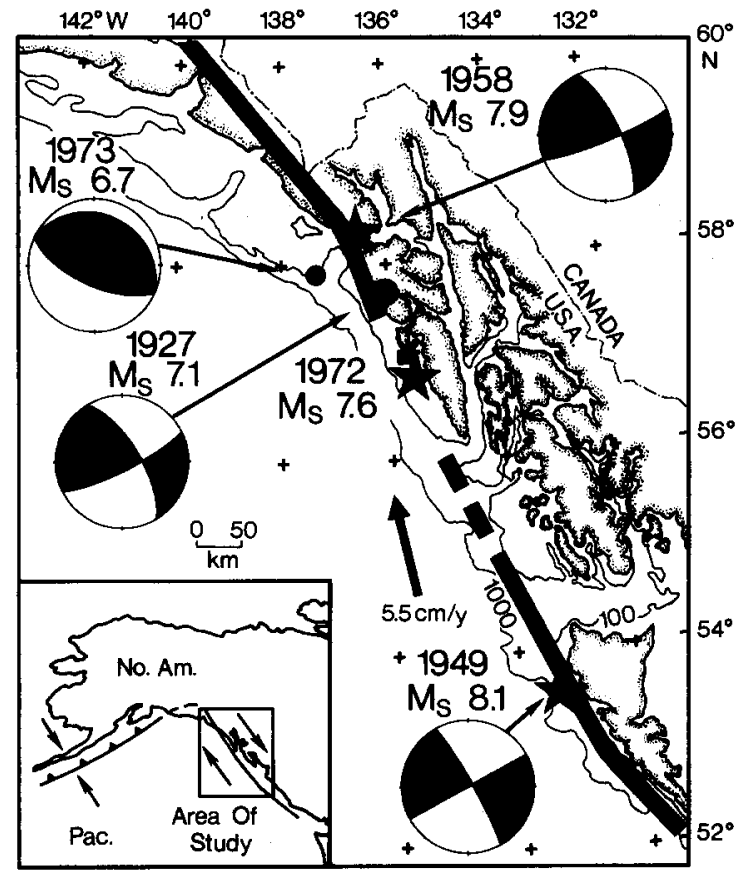

Fig. 1. Tectonic features and large earthquakes in southeastern Alaska. The stars represent the epicenters of the 1958, 1972, and 1949 large earthquakes and the circles represent the epicenters for the 1973 and 1927 events. The bold solid lines to the north and south represent the rupture zones of the 1958 and 1949 earthquakes, respectively. The broken line represents the extension of the 1949 rupture zone to an isolated aftershock cluster. Plate motion of the Pacific plate relative to North America is denoted by the bold arrow from the RM2 model of Minster and Jordan (1978). The asterisk marks the location of the Mt. Edgecomb volcano. Sitka is located $\sim 20 \mathrm{~km}$ due east of Mt. Edgecomb. The two bathymetric contours are in fathoms. The focal mechanisms represent the first-motion data for each of the four events located on the map. The inset map shows a schematic representation of the Pacific-North America tectonics.

Aleutian-Alaska arc to strike-slip along southeastern Alaska (Fig. 1). The Queen Charlotte fault is the offshore and southerly extension of the Fairweather fault to the south of Icy Point and presumably accommodates the dextral motion of the Pacific plate relative to the North America plate. The rate is $-5.6 \mathrm{~cm} \mathrm{a}^{-1}$ as determined by the RM2 model of Minster and Jordan (1978). The epicenters and rupture extents of the two large earthquakes that occurred in this region in 1958 and 1949 are indicated by the stars and bold solid lines, respectively.
The Queen Charlotte fault segment between the rupture zones of the 1958 St. Elias and 1949 Queen Charlotte earthquakes was thought to be a seismic gap (see Sykes, 1971). This seismic gap was apparently ruptured by the July 30, 1972 Sitka earthquake (Page, 1973). In addition to the above-mentioned three large earthquakes, two smaller events are also plotted in Fig. 1, the 1927 strike-slip earthquake $\left(M_{\mathrm{S}}=7.1\right)$, which is near the southern end of the 1958 rupture zone, and the 1973 thrust event $\left(M_{\mathrm{S}}=6.7\right)$ which occurred offshore to the southwest of the 1958 event.

Given the right-lateral sense of motion indicated by the 1958, 1927, and 1949 events along this fault, we also expect the 1972 earthquake to be right-lateral, and indeed the $P$ wave first-motion data confirm this expectation (see Fig. 2, and Perez and Jacob, 1980). If the NW-SE trending nodal plane is chosen to be the fault plane, then the fault plane has a strike of $347^{\circ}$, dip of $78^{\circ}$, and slip vector of $180^{\circ}$. This mechanism is very similar to the first-motion mechanism determined by Perez and Jacob (1980).

With $M_{\mathrm{S}}$ of 7.6, the 1972 Sitka earthquake is one of the largest strike-slip earthquakes that has occurred since the establishment of the World Wide Standardized Seismograph Network (WWSSN) in 1963. As described in the following section, the availability of strong ground motion

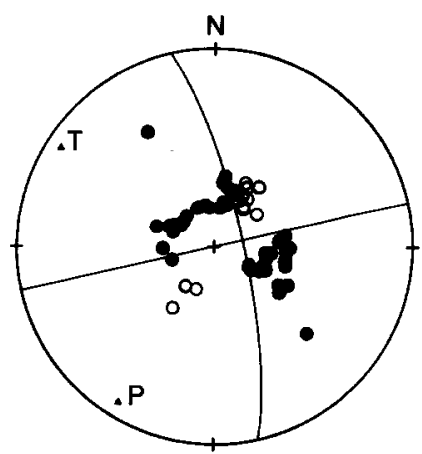

Fig. 2. P wave first-motion data and nodal plane solution for the 1972 Sitka event shown on a lower hemisphere equal area projection. All data are from WWSSN long-period records. Closed circles are compressional and open circles are dilatational first motions. $T$ represents the tensional axis and $P$ represents the compressional axis. The solution has a fault strike of $347^{\circ}$, a fault dip of $78^{\circ}$, and a slip vector of $180^{\circ}$. 
records for this event provides additional motivation to study the rupture process in detail. We have determined the source characteristics of this important strike-slip earthquake. The long-period surface waves are used to constrain the seismic moment, and the teleseismic $P$ waves are used to unravel the details of the rupture history. We were also able to obtain a quantitative description of the rupture process by tomographic inversion of the source time functions (see Ruff, 1987). As it is important to compare the rupture process of similar size events to document variations in the rupture mode, we contrast the 1972 Sitka earthquake with another large strike-slip event, the 1976 Guatemala earthquake.

\section{Accelerograms of the Sitka earthquake}

The study of near-field shaking is important in terms of earthquake hazards mitigation. Earthquake engineers originally developed and deployed accelerographs capable of recording the strong ground motions caused by large earthquakes. Even though many accelerograms have been recorded (see Jennings, 1983, for a brief review), there is still a lack of accelerograms from large $(M \approx 7.5)$ earthquakes. An accelerograph installed at the Sitka Observatory was triggered by the 1972 earthquake. The epicentral location is southwest of the Sitka Observatory; the minimum distance between this site and the probable fault plane is $\sim 50 \mathrm{~km}$. Strong ground motions at this distance are not simply related to the fault slip history, thus we shall not pursue any quantitative modeling. Our main purpose is to display the digitized accelerograms, ground velocities, and displacements.

The Sitka accelerograph is a standard AR-240 strong-motion recorder. There are calibration tests before and after the 1972 earthquake, the total duration of the triggered record is $\sim 55 \mathrm{~s}$, and there is apparent signal for the first 45-46 s. The developed records (NOAA-Seismological Field Survey) indicate the following component polarities and calibration information $(S$, sensitivity in $\mathrm{cm} \mathrm{g}^{-1}, \mathrm{~g}$, Earth's gravitational acceleration; $T$, seismometer period in seconds; $D$, damping): North, $S=7.04, T=0.052, D=0.59$; Down, $S=$ 9.39, $T=0.057, D=0.61$; West, $S=7.01, T=$ $0.049, D=0.57$; and the average film speed is 2.02 $\mathrm{cm} \mathrm{s}^{-1}$. The three-component paper copy accelerograms are digitized, interpolated at an interval of $0.01 \mathrm{~s}$, and corrected for sensitivity (Fig. 3). The peak accelerations are: $0.05 \mathrm{~g}$ Vertical, $0.09 \mathrm{~g}$ North, and $0.10 \mathrm{~g}$ West. These peak accelerations are basically compatible with the results for other large earthquakes (Page et al., 1975). There are pronounced long-period oscillations clearly visible in the horizontal traces: the oscillations in the

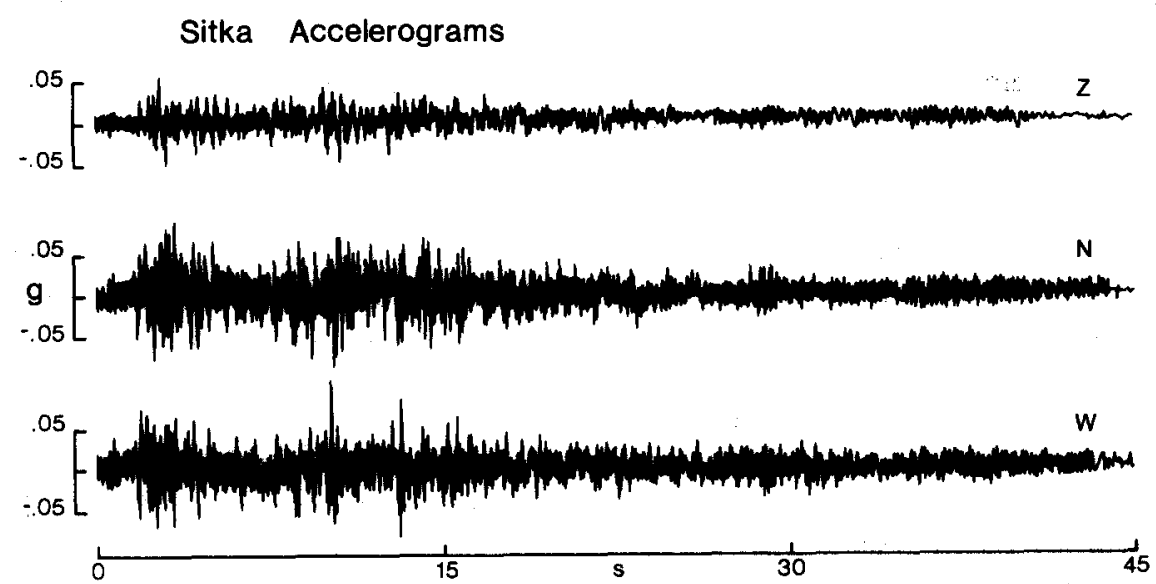

Fig. 3. Three components (up, north, west) of strong ground motion recorded by a AR-240 strong-motion recorder at the Sitka Seismological Observatory, Sitka, Alaska, $\sim 50 \mathrm{~km}$ away from the fault. Time-scale starts at the trigger time. The accelerograms are digitized and replotted at correct relative scale, given by $g\left(980 \mathrm{~cm} \mathrm{~s}^{-2}\right)$. 

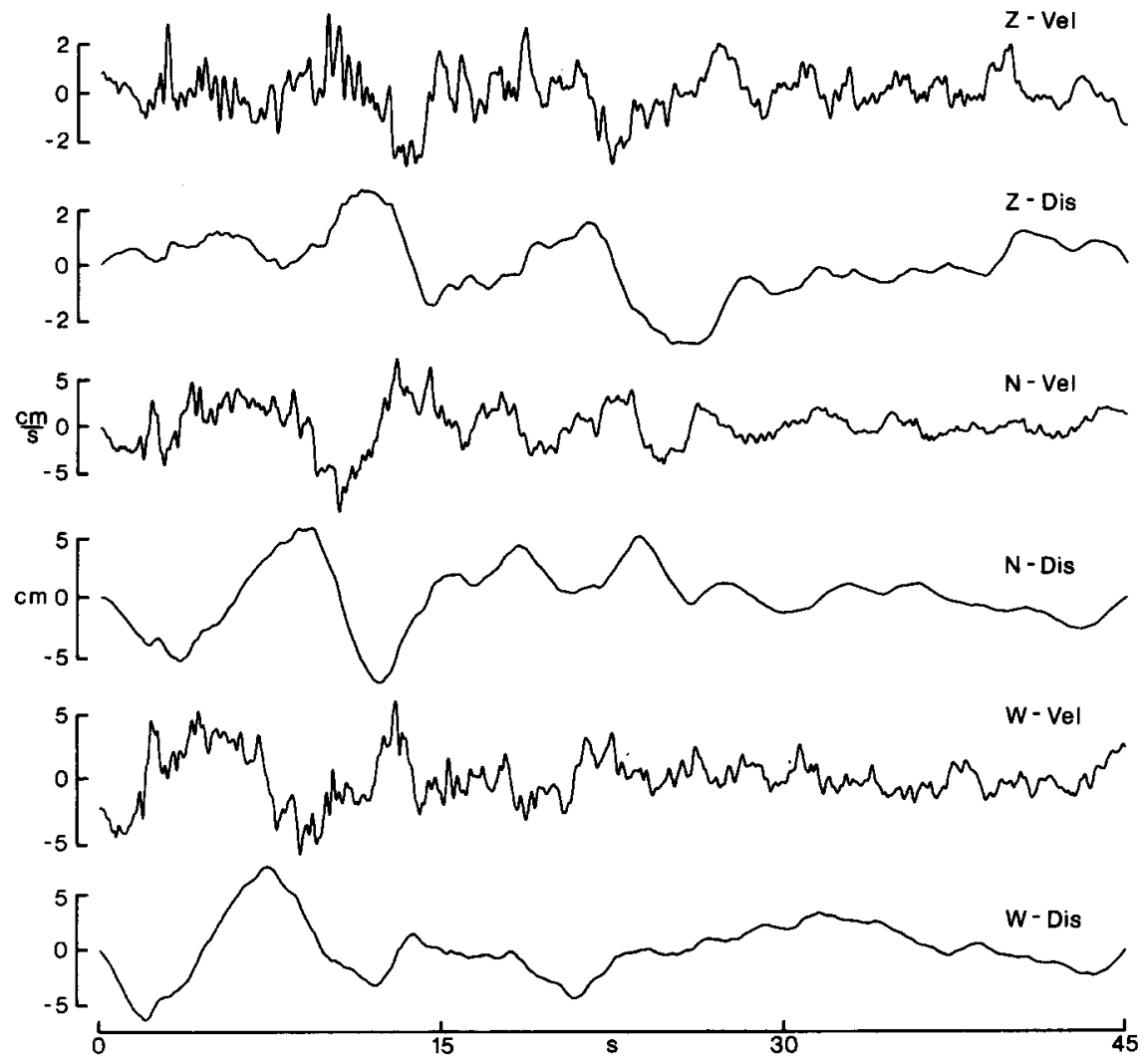

Fig. 4. Sitka accelerograms integrated to ground velocity (units of $\mathrm{cm} \mathrm{s}^{-1}$ ) and displacement (cm) traces for the vertical (top), north (middle), and west (bottom) components.

latter half of the records have an apparent period of $\sim 3.0 \mathrm{~s}$.

Earthquake engineers have developed various techniques to stably integrate an accelerogram to produce ground velocity and displacement. The Sitka accelerograms in Fig. 3 are integrated with a modification of the processing sequence described by Trifunac (1971). In contrast to the Ormsby filter described by Trifunac, our baseline filter has a finite duration with no time domain sidelobes. The frequency $(f)$ domain characteristics are a $f^{-4}$ asymptotic spectral decay that 'eliminates' $90 \%$ or more of the spectral amplitude for periods $>12 \mathrm{~s}$, and $10 \%$ or less for periods $<2.7 \mathrm{~s}$; while the Ormsby filter 'eliminates' $100 \%$ of the spectral amplitude for periods $>20 \mathrm{~s}$, and $0 \%$ for periods $<14 \mathrm{~s}$. Our filter is more conservative than Trifunac's as it partially filters any 'true' seismological signal with periods of 3-14 s, yet it adopts
Trifunac's long-period criterion in that essentially $100 \%$ of spectral amplitude for periods $>24 \mathrm{~s}$ is 'eliminated' from the accelerograms. As suggested by Trifunac (1971), this long-period exclusion is important as the displacement traces integrated from unfiltered traces have large baseline instabilities with a period of $\approx 30 \mathrm{~s}$.

The processed ground velocity and displacement traces are plotted in Fig. 4 for all three components. All times are relative to trigger time. Note that both horizontal components show a distinct peak in ground velocity at $\sim 13 \mathrm{~s}$. It is interesting that the horizontal velocities show a high correlation for the first $\approx 4 \mathrm{~s}$, with the initial ground velocity to the southeast for $2 \mathrm{~s}$ followed by ground velocity to the northwest. After analysis of the teleseismic waves, we will compare the source time functions to the Sitka ground motions. We first examine the aftershock distribution. 


\section{Aftershocks}

There are only six teleseismic 'aftershocks' of the Sitka event reported in the NEIS catalog (Fig. 5). Three aftershocks occurred within 1 month after the mainshock and the other three occurred in a period of 1-4 months. There are no reports of teleseismically recorded 1-day aftershocks. From the few events located to the south of the epicenter and the one far to the north, it is difficult to ascertain whether the rupture was unilateral to the south or possibly bilateral. Note that the one event to the north occurred months after the mainshock and is not located on the Fairweather fault; hence its association might be with the small 1973 thrust event rather than with the 1972 Sitka event.

Fortunately, Robert Page and colleagues recorded microaftershocks for this event and generously provided the epicentral data. Approximately 61 microaftershocks with $M \geq 2.5$ were recorded from August 9 to August 15, 1972 (see Fig. 6). These events fall into two regions: one region extends southeast from the epicenter to $\sim 56^{\circ} \mathrm{N}$; and the other region extends from $57^{\circ} \mathrm{N}$ to $57.5^{\circ} \mathrm{N}$ to the northwest of the epicenter. The former region abuts the 1949 aftershock region to

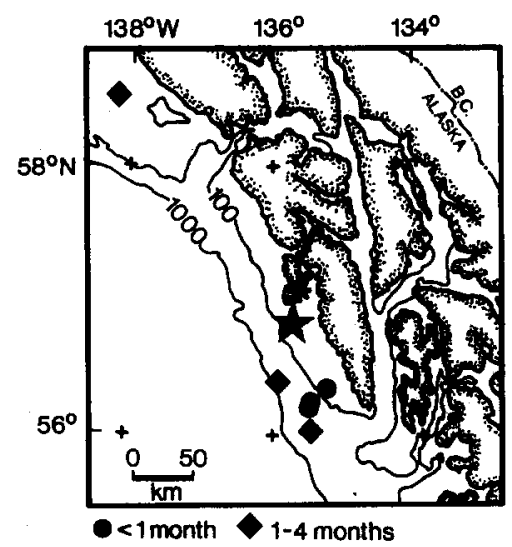

Fig. 5. Sitka region and the teleseismic aftershocks. The star is the epicenter of the 1972 Sitka earthquake. The asterisk is the location of Mt. Edgecomb. The solid circles are aftershocks with $m_{\mathrm{b}}$ between 5.1 and 5.6, recorded within 1 month and the solid diamonds are aftershocks with $m_{\mathrm{b}}$ between 4.0 and 5.0 , recorded within a period of 1-4 months. The bathymetric contours are in fathoms.

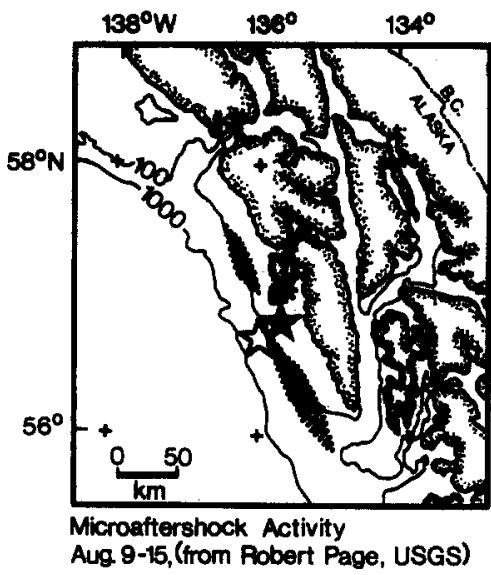

Fig. 6. Sitka region with the regions of concentrated microaftershock activity. The solid star is the ISC epicenter of the 1972 Sitka earthquake and the open star is the epicenter relocated by Robert Page and colleagues. The two hatched regions represent the microaftershock activity recorded from August 9 to August 15 by Page.

the south at $\sim 56^{\circ} \mathrm{N}$, and the latter abuts the 1958 and 1927 events to the north at $\sim 57.5^{\circ} \mathrm{N}$ to $58^{\circ} \mathrm{N}$. The total extent of the microaftershocks is $180 \mathrm{~km}$ and suggests that the seismic gap was filled (as concluded by Page, 1973). A curious feature in the distribution is the absence of microaftershocks between the epicenter and $\approx 57^{\circ} \mathrm{N}$ to the north. Although we cannot conclude that this zone was also quiescent with respect to the 1-day aftershocks, it clearly indicates some degree of spatial heterogeneity within the rupture zone. The microaftershock regions define a fault trend with a strike of $340^{\circ}\left(\mathrm{N} 20^{\circ} \mathrm{W}\right)$. This fault azimuth is identical to the azimuth of the RM2 plate motion vector between the Pacific and North American plates, suggesting that a strike-slip focal mechanism with a fault strike of $340^{\circ}$ may be a suitable average mechanism. We have modeled long-period Rayleigh waves in order to test whether the firstmotion mechanism is an appropriate average mechanism and to determine the seismic moment.

\section{Rayleigh waves}

The long-period Rayleigh waves are analyzed using a well-known tochnique originally developed 
by Kanamori (1970) to study large earthquakes. This analysis determines the focal mechanism and seismic moment and places constraints on the rupture direction and length. This technique has been successfully applied to many earthquakes by several investigators. For a focal mechanism that is close to pure strike-slip, Rayleigh waves are more sensitive to the variations in focal parameters than are Love waves, and the data analysis is more reliable for Rayleigh waves than for rotated WWSSN Love waves.

We have plotted a representative Rayleigh wave phase from one of the lobe stations to show the excellent long-period signal that is available in the raw WWSSN data (Fig. 7). The very-long-period 'mantle' waves are obvious in the observed seismograms. The vertical long-period component WWSSN seismograms are digitized for a group velocity window of $3.5-4.0 \mathrm{~km} \mathrm{~s}^{-1}$. All data and synthetic seismograms are filtered with a low-pass zero-phase filter with a smooth spectral truncation: a flat response from 0 to $4.3 \mathrm{mHz}$, and a half-cosine taper between 4.3 and $6.0 \mathrm{mHz}$. This filter isolates the very-long-period Rayleigh waves with a dominant period of $\sim$ 3-4 min (see filtered trace in Fig. 7). All 25 Rayleigh wave phases were

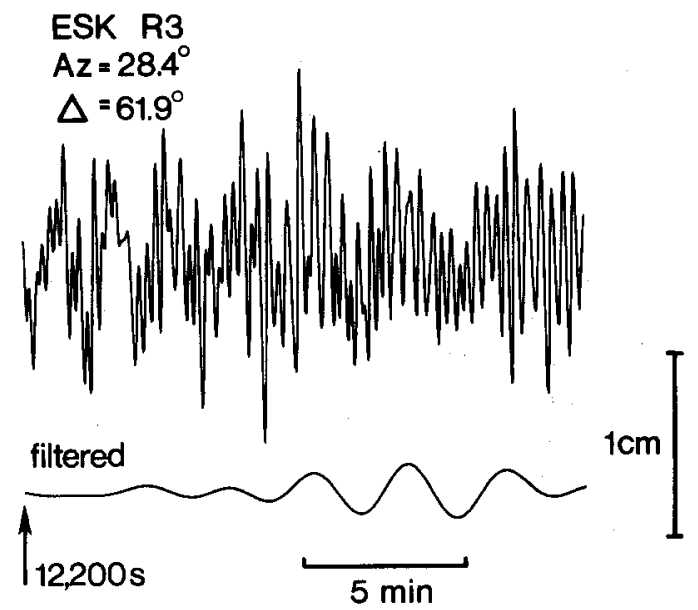

Fig. 7. Representative digitized (top) and filtered (bottom) long-period R3 Rayleigh wave at a lobe station (ESK, WWSSN vertical component). Start time is given in seconds from origin time. Amplitude scale is for the original record at ${ }^{2} 1500$ magnification. All Rayleigh waves are filtered with this same filter.

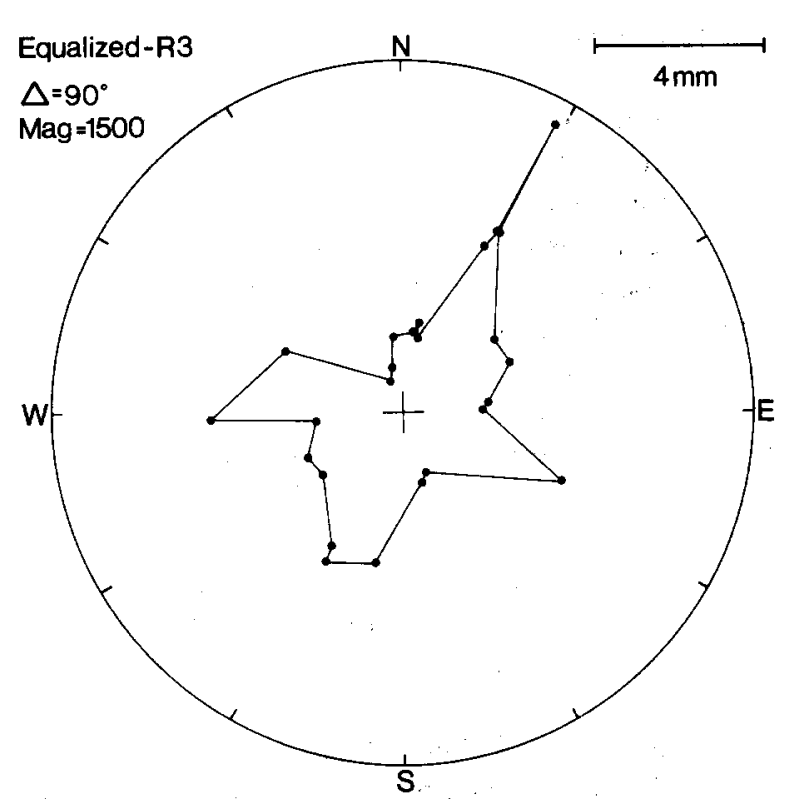

Fig. 8. Rayleigh wave radiation pattern based on 'raw' peakto-trough amplitudes. WWSSN Rayleigh wave phases are equalized to $R 3$ at a distance of $90^{\circ}$ and 1500 magnification. Amplitude scale is at upper right.

equalized to $\mathrm{R} 3$ at an epicentral distance of $90^{\circ}$ and a magnification of 1500 .

The peak-to-trough amplitudes of the filtered and equalized traces are plotted as a function of azimuth in Fig. 8. The source radiation pattern constrains the fault geometry; as one can see the larger amplitudes at the lobes decrease toward zero at the nodes. The four-lobed radiation pattern basically confirms that the overall focal mechanism is mostly strike-slip, and the NW-SE trending nodal direction is consistent with a NW-SE trending fault plane. Note that the average lobe amplitude of the equalized R3 phase is a few millimeters, i.e., comparable to the signal observed at ESK in Fig. 7. The anomalously large amplitude value in the northeast lobe is the AKU R3 phase. This large amplitude is not simply a calibration error as the R2 and R5 phases from AKU have normal amplitudes; we believe that it is a path effect (see Lay and Kanamori, 1985).

The traditional technique of focal mechanism determination from equalized WWSSN longperiod surface waves is a trial-and-error procedure whereby the maximum amplitudes of suitably 
filtered synthetic seismograms are compared with the observed amplitudes (see Kanamori, 1970). Kanamori and Given (1981) have demonstrated that high-quality digital recordings of long-period surface waves (from the IDA and SRO global networks) can be directly and reliably inverted for the focal mechanism. However, this procedure has not been thoroughly tested for hand-digitized WWSSN data. While the very-long-period amplitudes of WWSSN data might be somewhat more scattered than for IDA and SRO data, the waveforms are generally quite consistent. One shortcoming of the traditional technique is that nodal stations (which place strong constraints on the faulting geometry) always show a non-zero amplitude due to noise. Thus, we have added one step to the traditional trial-and-error procedure by isolating only the coherent part of the equalized surface waves.

Rayleigh waves from a strike-slip mechanism have the same wave shape at all azimuths for the equalized R3 phases, only the amplitude and polarity vary. Thus, we can use cross-correlation between a reference synthetic seismogram and the observed seismograms as a measure of the coherent signal (see Fig. 9). Using a focal mechanism of $\left(\phi=340^{\circ}, \delta=85^{\circ}, \lambda=175^{\circ}\right)$ at a depth of 16 $\mathrm{km}$, we created a synthetic seismogram at an azimuth of $25^{\circ}$ (lobe station) and then shifted and scaled the synthetic to produce the highest correlation with each observed phase: the resultant shifts and scale factors are the group delay and amplitude factor for that phase. The average group delay from the lobe phases is $20 \pm 16 \mathrm{~s}$ (sd). There does not appear to be any consistent azimuthal asymmetry associated with the delay times; thus this result is consistent with bilateral rupture. We then use the amplitudes to determine the seismic moment by scaling the synthetics to the data. The scale factors from the lobe stations give a seismic moment of $3 \times 10^{27} \mathrm{dyn} \mathrm{cm}$. This moment estimate is quite stable with respect to changes in the reference synthetic seismogram; i.e., use of the first-motion $347^{\circ}$ mechanism, focal depth of 33 $\mathrm{km}$, or use of a finite source.

Except for the aberrant AKU R3 phase, the average scale factors exhibit a clear symmetric four-lobed radiation pattern (Fig. 10). Further-

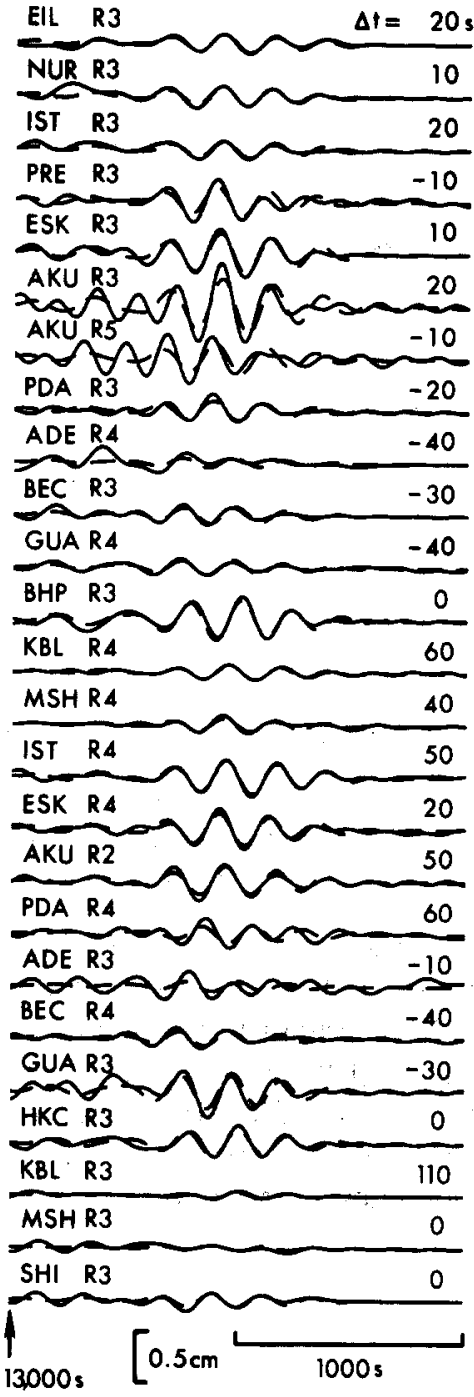

Fig. 9. Equalized R3 Rayleigh waves (solid traces) and best-fit synthetic seismograms (dashed traces) plotted as a function of azimuth clockwise from this north. The $\Delta t$ represents the delay time in seconds. The synthetics are generated for a depth of 16 $\mathrm{km}$ using the focal mechanism with $\phi=340^{\circ}, \delta=85^{\circ}, \lambda=$ $175^{\circ}$. All traces are from WWSSN stations, and are plotted at correct relative amplitude (amplitude scale for $\mathbf{1 5 0 0}$ magnification is at bottom). Start time is relative to earthquake origin time.

more, the nodes are better defined relative to the 'raw' amplitude pattern in Fig. 8. Synthetic radiation patterns are constructed at the same azimuths as the observed seismograms for both the $347^{\circ}$ and $340^{\circ}$ mechanisms. Both mechanisms produce 


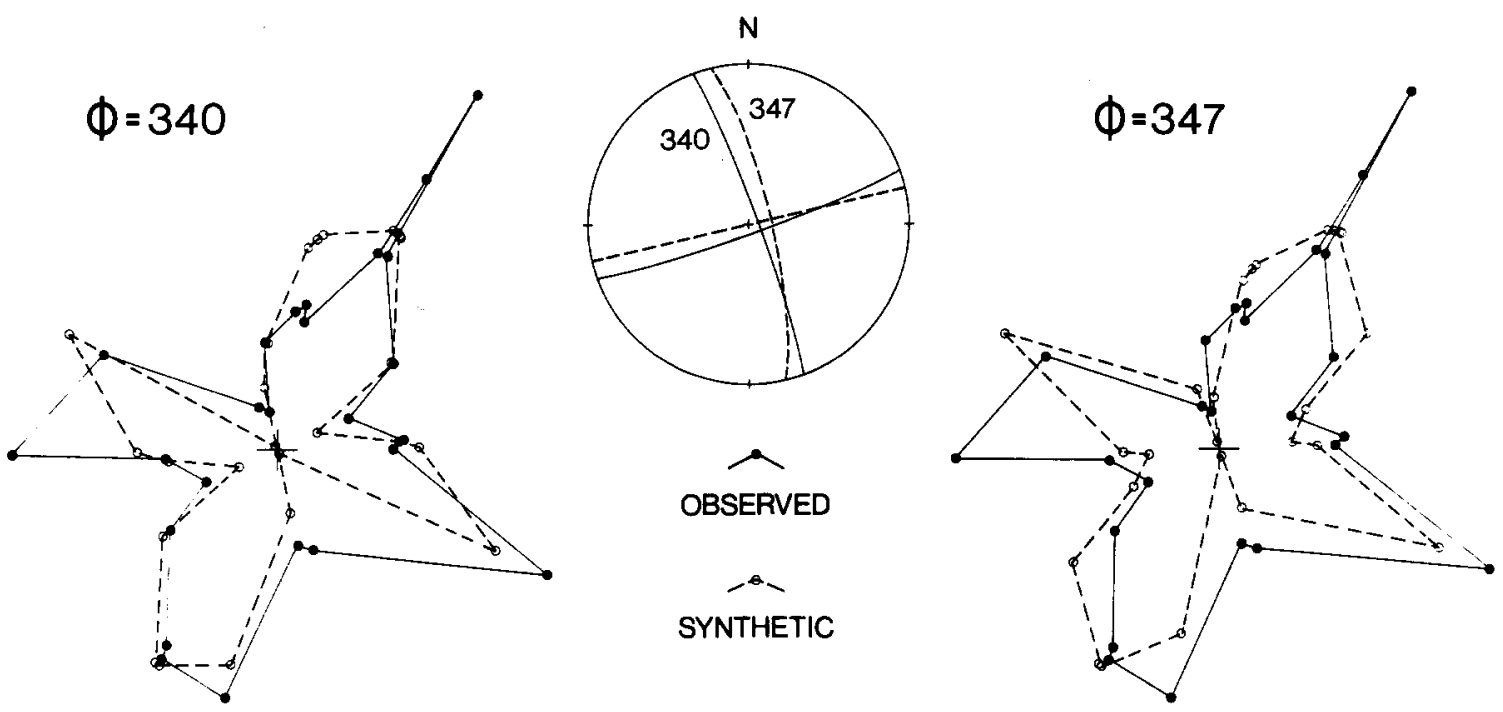

Fig. 10. Observed and synthetic Rayleigh wave radiation patterns. The observed pattern (solid dots) is generated from the cross-correlation scale factors, obtained by scaling a synthetic to each equalized Rayleigh phase, and then plotted as a function of azimuth (north at top). The synthetic patterns (open circles) are generated for two mechanisms (1) $\phi=340^{\circ}, \delta=85^{\circ}, \lambda=175^{\circ}$, and (2) $\phi=347^{\circ}, \delta=78^{\circ}, \lambda=180^{\circ}$. The synthetics are generated at the same azimuths as the observed and for a moment of $3 \times 10^{27}$ dyn $\mathrm{cm}$. Both the $340^{\circ}$ (solid) and $347^{\circ}$ (dashed) focal mechanisms are shown.

acceptable matches to the data. To summarize the surface wave analysis, either the first-motion mechanism or the $340^{\circ}$ mechanism is acceptable, the seismic moment is $3.0 \pm 0.5 \times 10^{27} \mathrm{dyn} \mathrm{cm}$, the overall average group delay is $20 \pm 16 \mathrm{~s}$, and the symmetric amplitudes and group delays argue against a dominant unilateral rupture model.

\section{P waves}

To determine the rupture process in more detail, we have modeled the teleseismic $P$ waves. Six of the 32 available $P$ waves recorded by WWSSN long-period instruments are plotted in Fig. 11 to show the azimuthal variation in the $P$ waves. Although the seismograms from any one sector of the focal sphere show the same waveshape, the character changes with azimuth. This variation is not solely dependent on the varying Green's function; that is, source time function directivity is important. To study this, the $\mathbf{P}$ waves were digitized and then deconvolved using the method of Ruff and Kanamori (1983). Source time functions are deconvolved with an interval of $2 \mathrm{~s}$ for a total duration of $120 \mathrm{~s}$, and the damping parameter

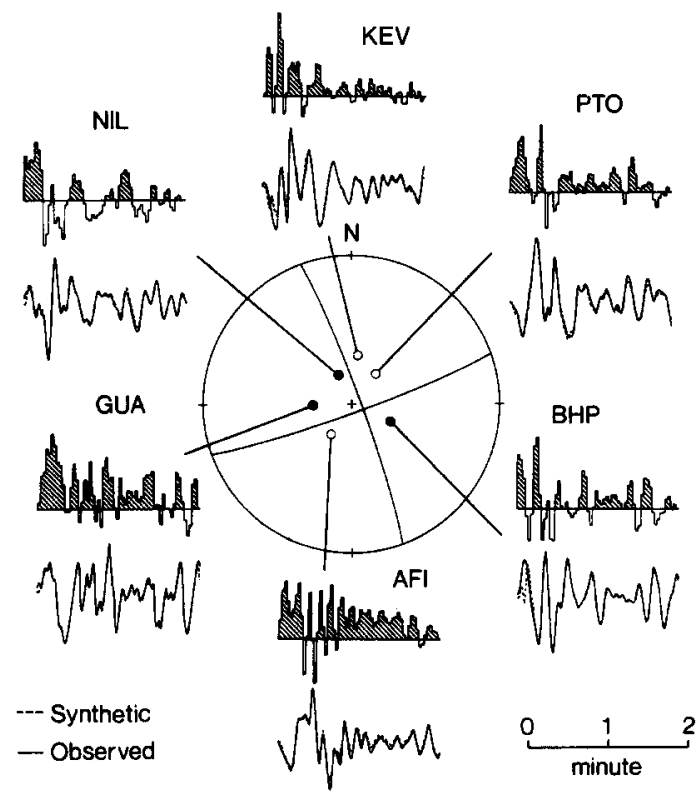

Fig. 11. Six representative source time functions deconvolved from WWSSN long-period $P$ waves plotted above the observed (solid) and synthetic (dashed) seismograms. The station locations are plotted with the focal mechanism $\left(\phi=340^{\circ}, \delta=85^{\circ}\right.$, $\lambda=175^{\circ}$ ). The source time functions are deconvolved with a point source at $10 \mathrm{~km}$ depth. Note that the characteristic shapes of the source time functions are different for the different azimuthal sectors. 


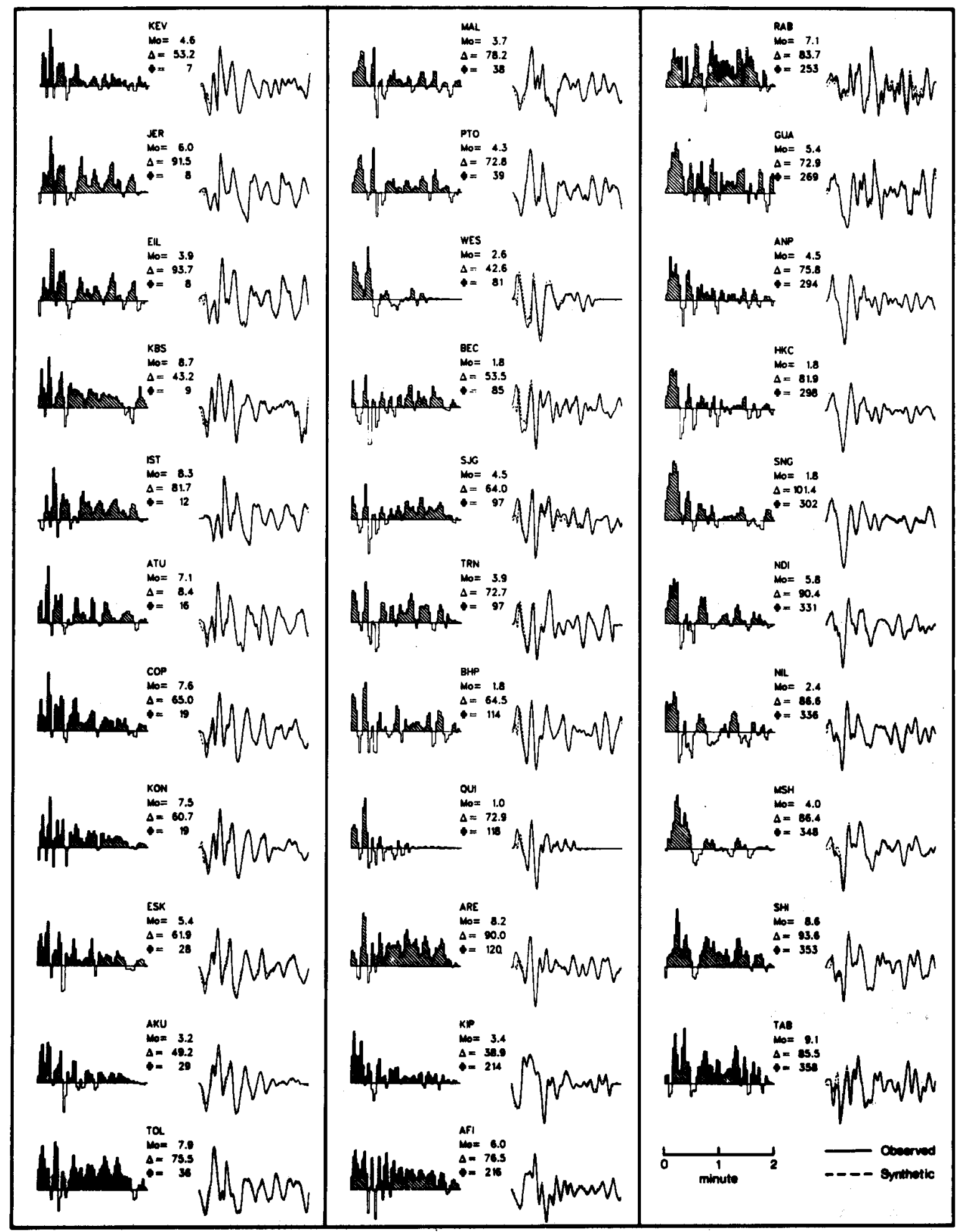

Fig. 12. Source time functions for the 1972 Sitka earthquake deconvolved from WWSSN long-period $P$ waves with the $340^{\circ}$ mechanism and a depth of $10 \mathrm{~km}$, with the observed (solid) and synthetic (dashed) seismograms. The stations are plotted in order of azimuth ( $\phi$, deg), with the epicentral distance $(\Delta, \mathrm{deg})$ and seismic moment $\left(M_{0}, \times 10^{27} \mathrm{dyn} \mathrm{cm}\right)$ also shown. 
value is 0.01 . The Green's functions include the surface reflections and 10 water reverberations with a water depth of $2 \mathrm{~km}$. We tested variations in the depth, e.g., a point source of $10 \mathrm{~km}$ and a distributed source depth of $0-10 \mathrm{~km}$, and the focal mechanism $\left(\phi=347^{\circ}, \delta=78^{\circ}, \lambda=180^{\circ}\right)$ and $\left(\phi=340^{\circ}, \delta=85^{\circ}, \lambda=175^{\circ}\right)$. We found that a model using the $340^{\circ}$ mechanism and a point source at $10 \mathrm{~km}$ was marginally better than the $347^{\circ}$ mechanism, with either a source depth of

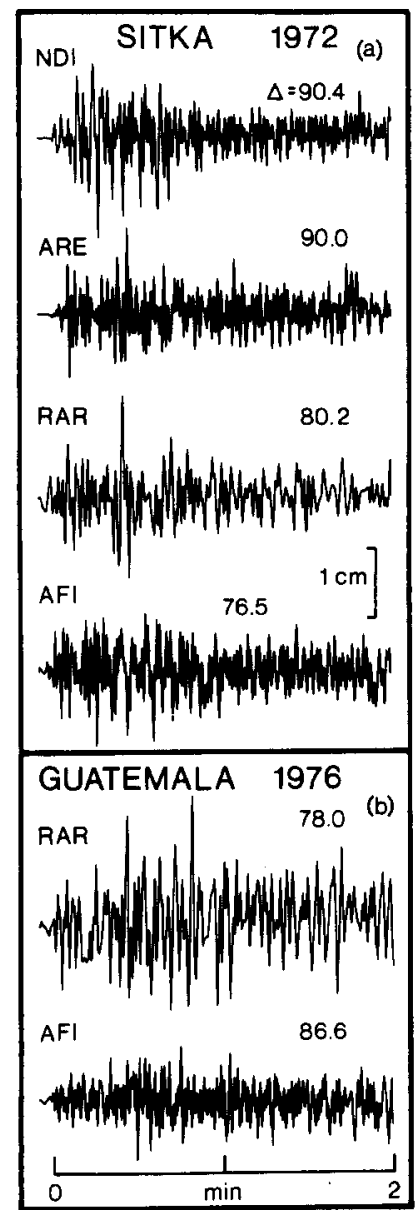

Fig. 13. Short-period vertical records for the (a) 1972 Sitka earthquake and (b) 1976 Guatemala earthquake $\left(M_{\mathrm{w}}=7.6\right)$ recorded at WWSSN stations. The traces are plotted at true relative amplitudes at a reference magnification of 25,000 . Note that the epicentral distances are all similar. The large amplitude oscillations are concentrated near the beginning for the Sitka event, but occur later in time for the Guatemala event.
$0-10 \mathrm{~km}$ or a point source of $10 \mathrm{~km}$, in terms of fit to the data and overall consistency. We also tried models using greater depths, but this produces inconsistent time functions. A clear and robust aspect of these tests is that the source time functions change azimuthally for all parameter combinations. The $340^{\circ}$ mechanism and a point source at $10 \mathrm{~km}$ are used to produce the time functions in Figs. 11 and 12.

The largest pulse of moment release occurs during the first 12-14 s for all source time functions. Plotting all $32 \mathrm{P}$ wave seismograms and their source time functions as a function of azimuth (Fig. 12) confirms that the character of the source time functions are similar in a given azimuthal sector. In detail, the pulses are quite complicated and the seemingly random variations after $1 \mathrm{~min}$ suggest no coherent moment release in the latter part of the source history. Since we cannot reliably associate features in the source time functions at different azimuths, we cannot perform the standard directivity analysis (see Beck and Ruff, 1984). Apparently there is interference between pulses generated along the fault plane, a characteristic of bilateral rupture.

A few of the WWSSN short-period $P$ wave records for the Sitka earthquake are shown in Fig. 13a. The duration of the large-amplitude shortperiod oscillations is similar to the duration of the dominant pulse in the source time functions. Although the envelopes of the short-period amplitudes appear consistent in shape and duration between stations, we cannot associate any distinct breaks. Thus, we are not able to detect the directivity of bilateral rupture in the short periods.

\subsection{Depth extent of faulting}

Continental strike-slip earthquakes generally tend to rupture over a shallow depth extent (for review see Mavko, 1981). The 1972 Sitka earthquake follows that tendency. It is possible to determine the lower depth extent of rupture given the observation that the complexity of the deconvolved source time function increases dramatically when the trial depth is deeper than the lower depth bound of moment release (Christensen and Ruff, 1985). Although we previously mentioned 

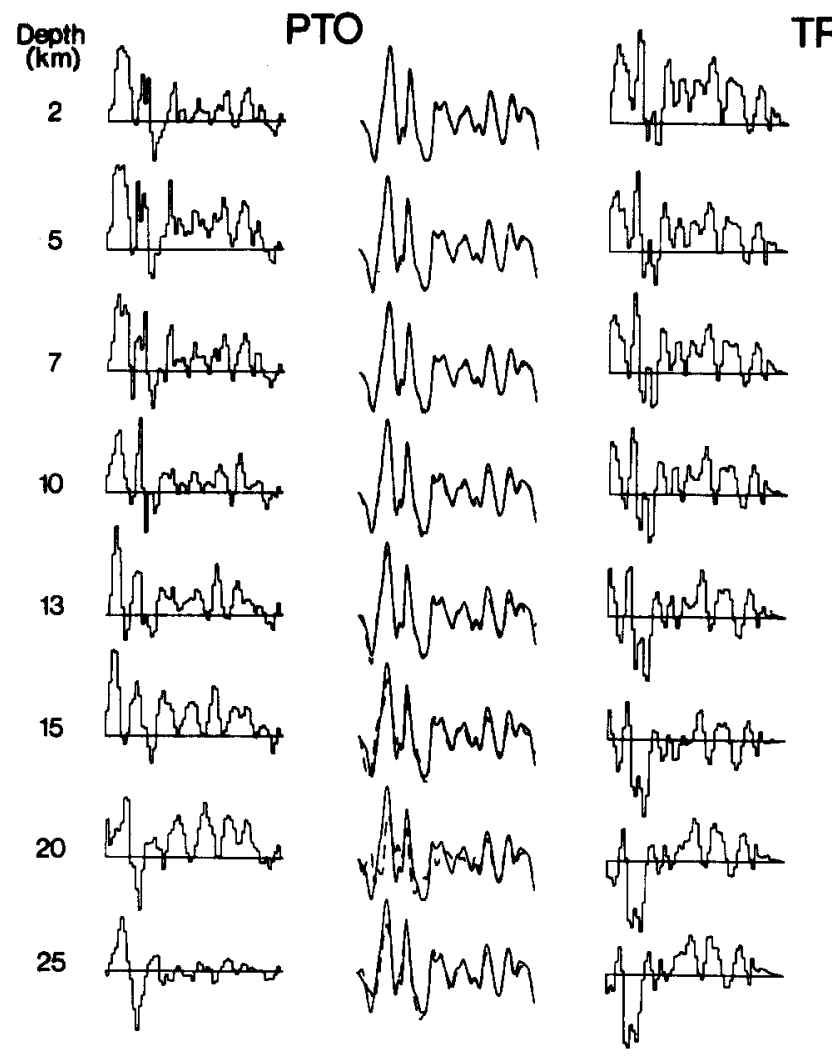

TRN

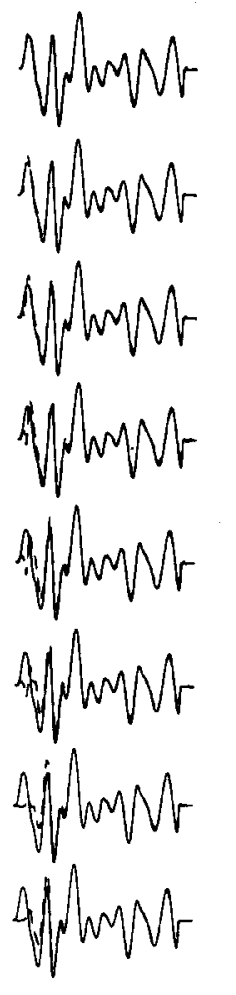

NIL

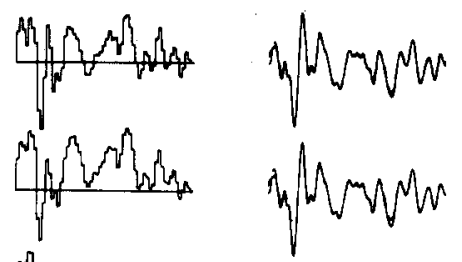

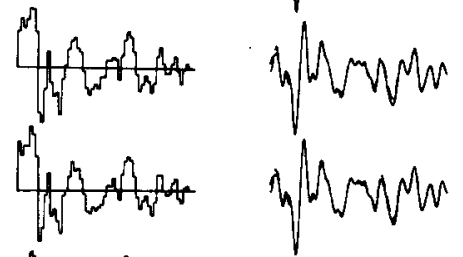

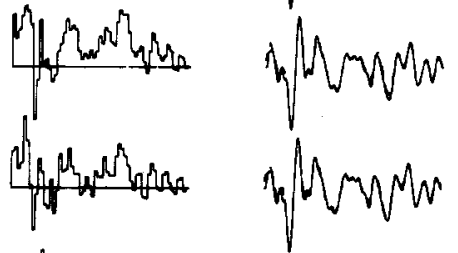

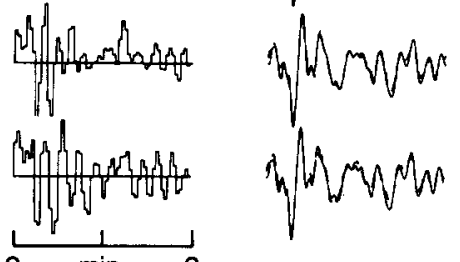

Fig. 14. Depth experiment for the Sitka earthquake. Source time functions deconvolved with the $340^{\circ}$ mechanism and a series of depths from long-period WWSSN P waves and the observed (solid) and synthetic (dashed) seismograms are plotted. Notice that the source time functions acquire extra later pulses, and the fit to the data degrades for a depth $>15 \mathrm{~km}$. This behavior suggests that the lower bound on the depth extent is $15 \mathrm{~km}$.

that the source time functions become inconsistent for trial depths $>10 \mathrm{~km}$, we now explicitly show the effect of increased complexity in Fig. 14. The source time functions and the observed and synthetic $\mathbf{P}$ wave seismograms for three representative stations are plotted for various assumed deconvolution depths, ranging from 2 to $25 \mathrm{~km}$ (Fig. 14). The source time functions display spurious pulses as the depth increases, and the match to the observed seismograms actually degrades for an assumed depth beyond $15 \mathrm{~km}$. From these observations, the lower depth bound on the rupture of the 1972 Sitka event is $15 \mathrm{~km}$, while the best estimate of the rupture extent is $0-10 \mathrm{~km}$.

\subsection{Tomographic imaging of the rupture process}

To quantitatively determine moment release along the fault, we use the formal inverse method devised by Ruff (1984, 1987). This method is particularly valuable for bilateral rupture where 'hand-picked' directivity analysis is not possible owing to sub-event interference. By inverting the 32 source time functions deconvolved from the $P$ waves, we obtain an image of the moment release in space and time. While the following rupture images use time functions deconvolved with the $340^{\circ}$ mechanism at a depth of $10 \mathrm{~km}$, we also inverted the time functions for the $347^{\circ}$ mechanism at a source depth of $0-10 \mathrm{~km}$, and found no significant differences in the resultant rupture images.

The imaging technique uses a priori estimates of the rupture direction and velocity, and iteratively determines the moment release distribution that best fits the observed time functions in a least squares sense. At each iteration, the method pro- 
duces a model image, which is a discretized version of the moment rate density function, and a comparison of the observed time functions and synthetic time functions generated for the model image. In all cases, we obtain a stable solution in just a few iterations. The best choice of the a priori parameters is determined by the combination of rupture direction and velocity that produces the best overall fit to the time functions. Overall fit to data is measured by $e$, which is the ratio of the error vector length to the data vector length: $e=|d-s| /|d|$, where $d$ is the data vector and $s$ is the synthetic vector produced by slant-stacking the image of the moment rate density function (see Ruff, 1987, for details). The model image consists of the moment rate density functions, for a duration of $120 \mathrm{~s}$, at regularly spaced intervals along the fault zone; we use a spatial interval of $10 \mathrm{~km}$ and a total fault extent of $240 \mathrm{~km}$, symmetric about the epicenter. Although we could simply specify the rupture azimuth to be $340^{\circ}\left(\mathrm{N} 20^{\circ} \mathrm{W}\right)$, we have formally tested this by inverting the time functions at azimuths of $310^{\circ}$, $340^{\circ}$, and $10^{\circ}$. Figure 15 clearly shows that $340^{\circ}$ produces the best fit to the time functions. Determination of the best overall rupture velocity for

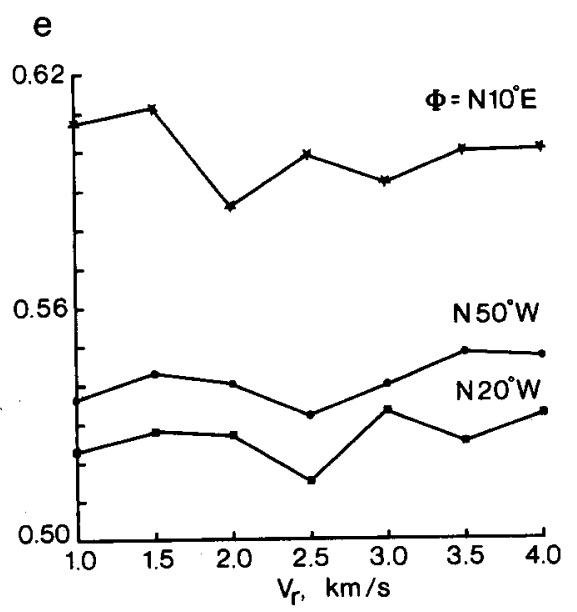

Fig. 15. Tomographic imaging error parameter $(e)$ at the tenth iteration versus a priori rupture velocity for three different rupture azimuths. The error parameter is the ratio of the length of the residual vector to that of the data vector. The 32 source time functions are normalized to the same peak amplitude and zero moment. $\mathrm{N} 20^{\circ} \mathrm{W}$ is clearly the best rupture azimuth and $2.5 \mathrm{~km} \mathrm{~s}^{-1}$ is the best overall rupture velocity. bilateral rupture is more difficult. While a rupture velocity of $2.5 \mathrm{~km} \mathrm{~s}^{-1}$ provides the best fit to the data, it is not as sharp a minimum as one might desire. A key question is how does the rupture image vary if we perturb the a priori velocity from $2.5 \mathrm{~km} \mathrm{~s}^{-1}$ ? We have performed many tests, and find that three features in the rupture image seem well resolved despite changes in the a priori parameters and the data set. These three pulses of moment release are indicated in Fig. 16 by the side bars with the star, dot, and cross. As we tested the various cases, we found that moment release features always show up at the epicentral region, between zero (the epicenter) and $\sim 40 \mathrm{~km}$ to the north, and also around $60-90 \mathrm{~km}$ to the south (dot, star, and cross symbols, respectively). Perturbing the rupture velocity will shift the spatial location of these pulses, but their existence and character does not change. It is important to note that the pulses to the north and south become more concentrated as part of the iterative process, confirming the resolution of the complicated bilateral rupture mode. The imaging method not only verifies that the rupture was in fact bilateral, but even more important, it locates the largest single pulse of moment release 30-50 $\mathrm{km}$ to the north of the epicenter. Since a substantial fraction of the moment release is contained in the region from the epicenter north to this pulse, we conclude that the rupture started at the main asperity. The location of the main asperity relative to the aftershocks seems somewhat unusual: the main asperity includes the quiescent zone between the epicenter and the northern microaftershock region, and the largest pulse of moment release occurs in the vicinity of the boundary between the quiescent zone and the northern region. Tomographic imaging also computes the time-integrated moment density along the fault zone (this function is plotted in Fig. 17). The three regions of consistently determined moment release are represented by the same symbols as in Fig. 16. This image has a total seismic moment of $3 \times 10^{27}$ dyn $\mathrm{cm}$, rather than the larger mean value from the single-station deconvolutions. Since we have allowed the fault dimensions to extend to $\pm 120 \mathrm{~km}$ from the epicenter, a small amount of moment release in Fig. 17 occurs outside the probable 


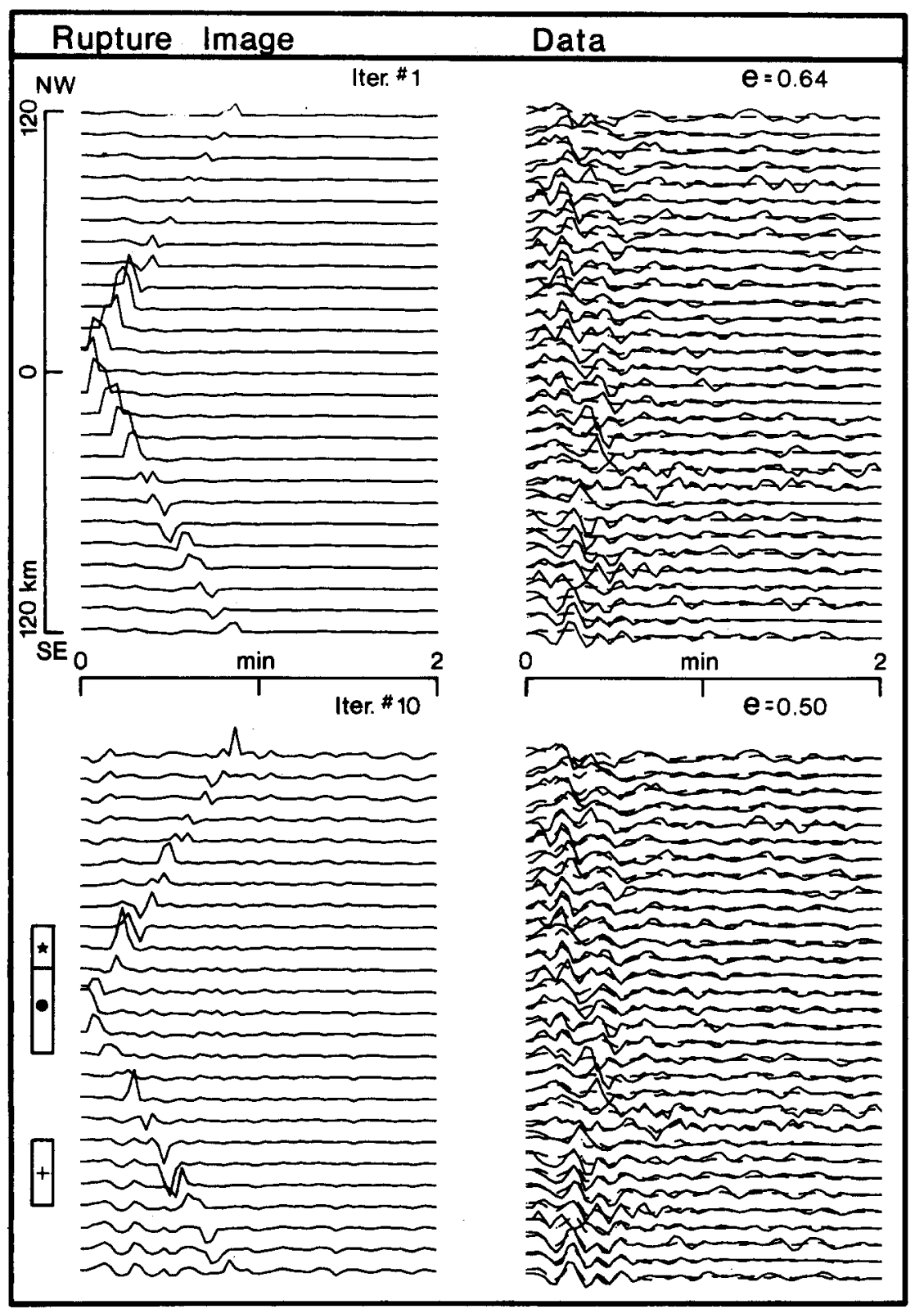

Fig. 16. Overall best image of moment release for the Sitka earthquake. The a priori rupture direction and velocity are $340^{\circ}$ and 2.5 $\mathrm{km} \mathrm{s}^{-1}$. The first and tenth iterations are plotted at top and bottom, respectively. Rupture images are to the left, with the moment rate density plotted as a function of time (horizontal axis) at various locations along the fault (vertical axis). Epicenter is at $0 \mathrm{~km}$. Data are the 32 source time functions: observed (solid traces) are plotted as a function of the directivity parameter, and the synthetic time functions (dashed) are obtained by slant-stacking the rupture image to the left. Source time functions are normalized to $3 \times 10^{27}$ dyn $\mathrm{cm}$, and the error parameter is shown. Well-resolved pulses of moment release are in the epicentral region (represented by the bar with a dot), just north of the epicenter (star), and at the southern terminus of rupture (cross). 


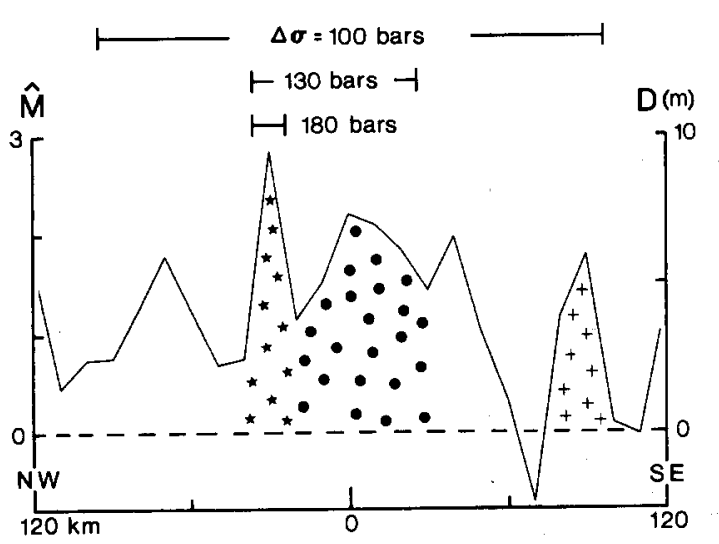

Fig. 17. Moment density and seismic displacement along the fault, from the best overall rupture image (tenth iteration in Fig. 16). The moment density function $\hat{M}$, is the time integral of the traces in Fig. 16, and has units of $10^{25}$ dyn $\mathrm{cm} \mathrm{km}^{-1}$. The seismic displacement along the fault (in $\mathrm{m}$ ) is obtained by dividing the moment density by $(\mu W)$, with $\mu=3 \times 10^{11}$ dyn $\mathrm{cm}^{-2}$ and $W=10 \mathrm{~km}$. Three consistent regions of moment release are: the epicentral region (dots), the pulse at $30 \mathrm{~km}$ to the NW (stars), and the secondary asperity at the southern end of rupture (crosses). The overall fault-averaged stress drop is shown at top for a fault length of $180 \mathrm{~km}$ (bar), while the dominant asperity stress drop is 130 bars, and the stress drop for the largest pulse of moment release is 180 bars.

rupture extent. Since tomographic imaging tends to smooth out concentrations of moment release (see Ruff, 1987), we must view Fig. 17 as a filtered version of the seismic moment density. Nevertheless, it is clear that the moment release is greater in the region just north of the epicenter and at the southern terminus of the rupture, which abuts the northern edge of the 1949 rupture zone. We will discuss the seismic displacement and stress drop in the following section.

\section{Seismic displacement, recurrence times, and stress drop}

The microaftershock regions recorded by Page and colleagues for the 1972 event suggest that the rupture extended bilaterally for $180 \mathrm{~km}$. The Rayleigh waves and $P$ waves indicate that this event has a seismic moment of $3 \times 10^{27} \mathrm{dyn} \mathrm{cm}$ and a shallow depth extent, $-0-10 \mathrm{~km}$. Furthermore, tomographic imaging identifies regions within the fault zone of concentrated moment release. We now use this information to discuss seismic displacement, stress drop, and recurrence time. First we consider the fault-averaged quantities.

The fundamental seismic moment formula relates the average displacement to seismic moment $\left(M_{0}\right)$, fault area $(A)$, and shear modulus $(\mu)$ as: $D=M_{0} / \mu A$. If we use $3 \times 10^{27} \mathrm{dyn} \mathrm{cm}, 10 \times 180$ $\mathrm{km}^{2}$, and $3 \times 10^{11} \mathrm{dyn} \mathrm{cm}^{-2}$ for $M_{0}, A$, and $\mu$, the average seismic displacement over the entire fault is $-6^{\circ} \mathrm{m}$. How does this compare with the accumulated tectonic displacement? Sykes et al. (1981) have suggested that an earthquake occurring on March 18, 1848 may have ruptured a portion of the Queen Charlotte-Fairweather fault system either in that of the 1958 rupture zone or in the 1972 Sitka rupture zone. If indeed this 1848 event did rupture the fault segment near Sitka, there would be $\sim 7 \mathrm{~m}$ of accumulated tectonic displacement given the average rate of motion between the North American-Pacific plates of $5.6 \mathrm{~cm} \mathrm{a}^{-1}$ (Minster and Jordan, 1978). Thus the average seismic displacement is comparable to the tectonic displacement accumulated since 1848. However, we know that the moment release is concentrated at the asperities where the seismic displacement will be larger than the average value. Since the moment density function in Fig. 17 gives seismic moment per unit fault length, the horizontally variable seismic displacement is given by dividing the moment density by the shear modulus and fault width. The seismic displacement averaged over the epicentral asperity (the $60 \mathrm{~km}$ long region denoted by the star and dot symbols) is $7 \mathrm{~m}$, though the peak displacement is $>9 \mathrm{~m}$ at $30 \mathrm{~km}$ NW of the epicenter (Fig. 17). Since the maximum fault displacement is $>9 \mathrm{~m}$, it is still an open question whether the 1848 event ruptured through the main asperity or not. Given these uncertainties, we consider the epicentral region of high moment release a 'dominant' asperity in that all the accumulated tectonic displacement is released by seismic displacement during the largest earthquake along the plate boundary segment. It is curious that the high displacement pulse that occurs $13 \mathrm{~s}$ after rupture initiation at $30 \mathrm{~km} \mathrm{NW}$ is located immediately adjacent to Mt. Edgecomb (Fig. 5). This is also the time at which a large 
pulse in both horizontal components of ground velocity occurs at the Sitka Observatory (Fig. 4).

We have also determined the stress drop for the 1972 Sitka event. The stress-drop formula $\Delta \sigma=$ $(2 / \pi) \mu(D / W)$ is valid for long strike-slip faults that rupture to the surface, where $W$ is fault width. Since we observe $M_{0}$, rather than $D$, rewrite $D$ as $M_{0} /(\mu L W)$, then the above formula is $\Delta \sigma=(2 / \pi)\left(M_{0} / L W^{2}\right)$, where $L$ is fault length. This formula can also be applied to subsections of the fault where $M_{0}$ is the moment over subsection fault length, $L$.

First we calculate the average stress drop over the entire fault with a width of $10 \mathrm{~km}$, a length of $180 \mathrm{~km}$, a moment of $3 \times 10^{27} \mathrm{dyn} \mathrm{cm}$; the average stress drop is then 100 bars. Since $\Delta \sigma$ depends on fault width as $\left(1 / W^{2}\right)$, increasing $W$ by $50 \%$ to $15 \mathrm{~km}$ decreases the stress drops by about a factor of two. As the moment release is concentrated in the epicentral region, we compute the main asper- ity stress drop by using the moment in the star and dot regions and a length of $60 \mathrm{~km}$, yielding a value of 130 bars. Although the simple stress drop formula is no longer strictly valid, we also calculate an approximate local stress drop of 180 bars at the pulse of moment release that occurs at $13 \mathrm{~s}$ adjacent to Mt. Edgecomb. In conclusion, the displacement averaged over the dominant asperity equals the tectonic displacement accumulated since 1848 , and the 'asperity' stress drop in the epicentral region is $\mathbf{1 3 0 - 1 8 0}$ bars, while the entire fault-averaged stress drop is -100 bars.

\section{Comparison with the 1976 Guatemala earth- quake}

It is interesting to compare the rupture process of the Sitka event with another large strike-slip event of similar seismic moment, the February 4,

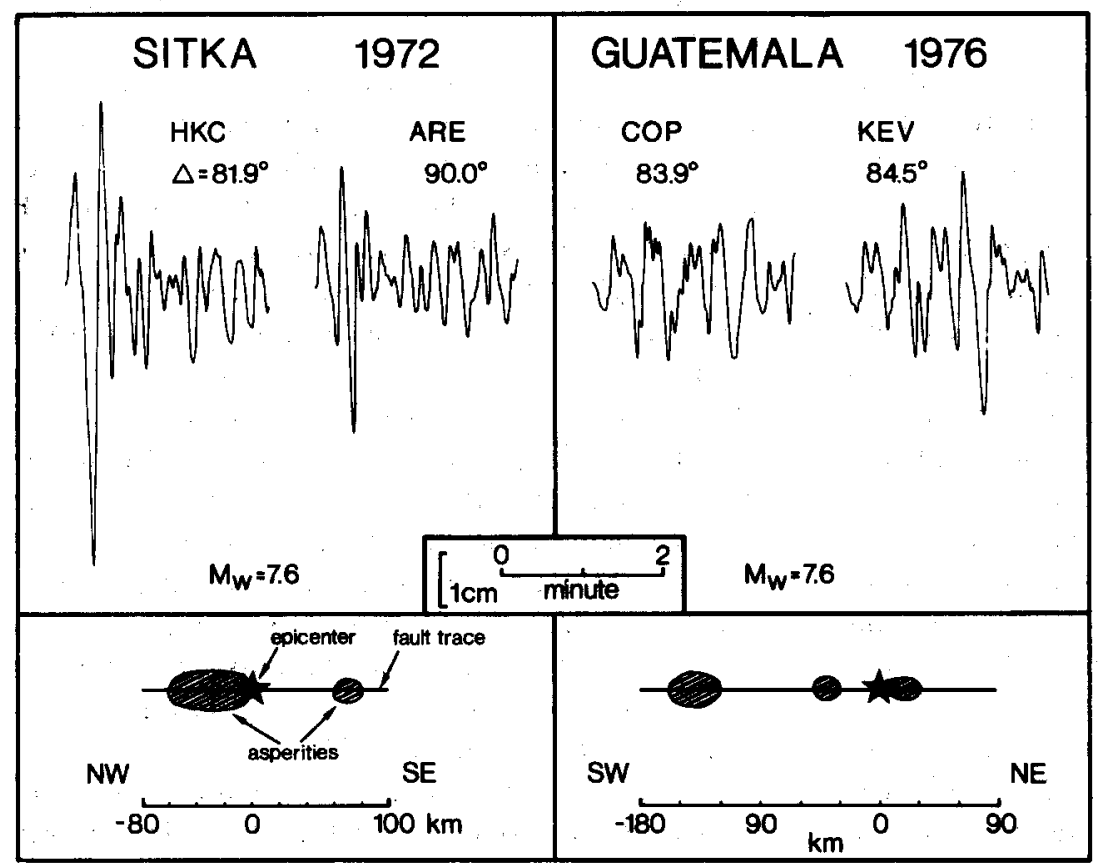

Fig. 18. Comparison of the Sitka and Guatemala strike-slip earthquakes. (Top) WWSSN long-period P waves for both the 1972 Sitka and the 1976 Guatemala earthquakes. Station codes and epicentral distances are listed for each seismogram, and $M_{w}$ is listed for both events. Amplitude scale refers to trace amplitude on original records at 1500 magnification. (Bottom) Schematic representations of the asperity distributions along the faults. Stars represent the epicenters, solid lines are the fault traces, and the hatched regions ${ }^{\text {tare }}$ the asperities, i.e., concentration of moment release. While the Sitka earthquake rupture initiated at the dominant aspetity, the Guatemala rupture started at a secondary asperity. 
1976, Guatemala earthquake (Fig. 18). The rupture processes for both events appear quite different just from the $P$ wave seismograms. We have shown that the rupture of the 1972 Sitka event initiated at the main asperity and it is obvious in the two representative $\mathbf{P}$ wave seismograms plotted in Fig. 18 that the largest pulse occurs in the beginning. This is in contrast to the 1976 Guatemala event. Kikuchi and Kanamori (1982) inverted the $P$ waves to determine the spatial variation along the fault, concluding that the dominant pulse occurs $\sim 90 \mathrm{~s}$ after rupture initiation and about $150 \mathrm{~km} \mathrm{SW}$ of the epicenter (Fig. 18). Also shown in Fig. 18 is a schematic representation of the asperity distribution along the fault planes for both events. For the Sitka event, the epicenter is at the main asperity but the epicenter and main asperity for the Guatemala event are separated by $150 \mathrm{~km}$. We can also observe these differences in the peak amplitudes of the short-period P wave records (Fig. 13), which occur sooner for the Sitka earthquake (a) than for the Guatemala earthquake (b).

Rupture mode variability is now well documented for large underthrusting events at subduction zones. For example, while the rupture initiation for the 1979 Colombia $\left(M_{\mathrm{W}}=8.1\right)$ event occurred $\approx 40 \mathrm{~km}$ from the main asperity (Beck and Ruff, 1984), the large events along the Kurile arc generally initiate at main asperities (Schwartz and Ruff, 1987). The rupture modes of the Sitka and Guatemala earthquakes represent rupture initiation and termination at the dominant asperities, respectively. The asperity distribution has been determined for only a few large 'plate-boundary' strike-slip events; the rupture for both the 1975 North Atlantic event $\left(M_{\mathrm{W}}=7.7\right.$; see Lynnes and Ruff, 1985) and the 1981 Macqurie Ridge event $\left(M_{\mathrm{W}}=7.6\right.$; see Ruff, 1983) initiated at main asperities. However, both these events occurred in oceanic lithosphere with transitional tectonic settings and thus are not good analogues for the Sitka and Guatemala earthquakes. In summary, the Sitka and Guatemala earthquakes represent the end-member rupture modes along well-developed transform boundaries; rupture initiation at the main asperity (Sitka), and rupture termination at the main asperity (Guatemala).

\section{Conclusions}

Seismic gaps along plate boundaries are presumably regions of high strain accumulation and thus increased likelihood of the occurrence of large earthquakes. In the context of the asperity/barrier model, the dominant asperity only slips in the largest earthquake during the earthquake cycle and therefore accumulates all the tectonic displacement since the previous large earthquake. The July 30,1972 Sitka earthquake $\left(M_{\mathrm{S}}=7.6\right)$ ruptured a region on the Queen Charlotte fault along the North America-Pacific plate boundary recognized as a seismic gap. Microaftershocks suggest that this event ruptured bilaterally for $180 \mathrm{~km}$, filling the gap between the 1958 and 1949 rupture zones. It is possible that an earthquake in 1848 ruptured the same portion of the Queen Charlotte fault as the Sitka event. If the 1848 earthquake did indeed rupture the portion of the fault near Sitka, then the accumulated displacement is $-7 \mathrm{~m}$ for a plate motion rate of 5.6 $\mathrm{cm} \mathrm{a}^{-1}$.

The seismic moment of the Sitka event is $3 \times$ $10^{27} \mathrm{dyn} \mathrm{cm}$, based on our analysis of the longperiod Rayleigh waves, which gives $M_{\mathrm{W}}=7.6$. Deconvolution of the teleseismic long-period $\mathrm{P}$ waves determines the depth extent to be $0-10 \mathrm{~km}$. Tomographic inversion of the deconvolved time functions indicates that the rupture initiated at the dominant asperity, and that the few teleseismic aftershocks at the southern terminus of rupture coincide with a secondary asperity. While the overall average displacement is $6 \mathrm{~m}$, the average displacement of the main asperity in the epicentral region is at least $7 \mathrm{~m}$. The asperity stress drop is 130 bars, while the fault averaged stress drop is 100 bars. The largest single pulse of moment release occurred $13 \mathrm{~s}$ after rupture initiation, adjacent to Mt. Edgecomb. This pulse may correspond to a coherent pulse in ground velocity recorded at the Sitka Observatory $13 \mathrm{~s}$ after trigger time of the accelerograph.

The initiation of the Sitka rupture at the main asperity contrasts with the 1976 Guatemala strike-slip event, where the main asperity occurred $150 \mathrm{~km}$ away from the epicenter. We can also observe the differences between the two 
earthquakes in the short-period records where the larger amplitudes are concentrated toward the beginning of the Sitka records, but occur later in time for the Guatemala records. These two plateboundary events clearly demonstrate the variability in the rupture process of large strike-slip events.

\section{Acknowledgments}

Dr. Robert Page kindly provided the results of his microaftershock study, and the Sitka Observatory staff generously loaned a high-quality copy of the Sitka strong ground motion recording.

We thank Chris Lynnes for his assistance in the initial phase of this study, and for his constructive comments on the final results. This research was supported by grants from the National Science Foundation (EAR8351515 and EAR8407786) and the Shell Companies Foundation to L.J.R.

\section{References}

Beck, S. and Ruff, L., 1984. The rupture process of the great 1979 Colombia earthquake: evidence for the asperity model. J. Geophys. Res., 89: 9281-9291.

Christensen, D. and Ruff, L., 1985. Analysis of the trade-off between hypocentral depth and source time function. Bull. Seismol. Soc. Am., 75: 1637-1656.

Fedotov, S.A., 1965. Regularities of the distribution of strong earthquakes in Kamchatka, The Kuril Islands, and northeast Japan. Trudy Inst. Fiz. Zemli, Akad. Nauk S.S.S.R., 36: 66-93.

Jennings, P.C., 1983. Engineering seismology. In: H. Kanamori and E. Boschi (Editors), Earthquakes: Observation, Theory, and Interpretation. North-Holland, Amsterdam, pp. 138-173.

Kanamori, H., 1970. Synthesis of long-period surface waves and its application to earthquake source studies, Kurile Islands earthquake of October 13, 1963. J. Geophys. Res., 75: 5011-5027.

Kanamori, H. and Given, J., 1981, Use of long-period surface waves for rapid determination of earthquake source parameters. Phys. Earth Planet. Inter., 27: 8-31.

Kelleher, J., Savino, J., Rowlett, H. and McCann, W., 1974. Why and where great thrust earthquakes occur along island ares. J. Geophys. Res., 79: 4889-4899.

Kikuchi, M. and Kanamori, H., 1982. Inversion of complex body waves. Bull. Seismol. Soc. Am., 72: 491-506.
Lay, T. and Kanamori, H., 1985. Geometric effects of global lateral heterogeneity on long-period surface wave propagation. J. Geophys. Res., 90: 605-621.

Lynnes, C.S. and Ruff, L.J., 1985. Source process and tectonic implications of the great 1975 North Atlantic earthquake. Geophys. J. R. Astron. Soc., 82: 497-510.

Mavko, G.M., 1981. Mechanics of motion on major faults. Ann. Rev. Earth Planet. Sci., 9: 81-111.

McCann, W.R., Nishenko, S.P., Sykes, L.R. and Krause, J., 1980. Seismic gaps and plate tectonics: seismic potential for major plate boundaries. Pure Appl. Geophys., 117: 1082-1147.

Minster, J.B. and Jordan, T.H., 1978. Present-day plate motions. J. Geophys. Res., 83: 5331-5354.

Mogi, K., 1969. Some features of recent seismic activity in and near Japan, 2, Activity before and after great earthquakes. Bull. Earthquake Res. Inst. Univ. Tokyo, 47: 395-417.

Page, R.A., 1973. The Sitka, Alaska, earthquake of 1972-An expected visitor. Earthquake Inform. Bull., U.S. Geol. Surv., Reston, VA, 5: 4-9.

Page, R.A., Blume, J.A. and Joyner, W.B., 1975. Earthquake shaking and damage to buildings. Science, 189: 601-608.

Perez, O.J. and Jacob, K.H., 1980. Tectonic model and seismic potential of the eastern Gulf of Alaska and Yakataga seismic gap. J. Geophys. Res., 85: 7132-7150.

Ruff, L.J., 1983. Fault asperities inferred from seismic body waves. In: H. Kanamori and E. Boschi (Editors), Earthquakes: Observation, Theory, and Interpretation. NorthHolland, Amsterdam, pp. 251-276.

Ruff, L.J., 1984. Tomographic imaging of the earthquake rupture process. Geophys. Res. Lett., 11: 629-632.

Ruff, L.J., 1987. Tomographic imaging of seismic sources. In: G. Nolet (Editor), Seismic Tomography. Reidel, Amsterdam, pp. 339-366.

Ruff, L.J. and Kanamori, H., 1983. The rupture process and asperity distribution of three great earthquakes from longperiod diffracted P-waves. Phys. Earth Planet. Inter., 31: 202-230.

Schwartz, S.Y. and Ruff, L.J., 1987. Asperity distribution and earthquake occurrence in the southern Kurile Islands arc. Phys. Earth Planet. Inter., 49: 54-77.

Sykes, L.R., 1971. Aftershock zones of great earthquakes, seismicity gaps, earthquake prediction for Alaska and the Aleutians. J. Geophys. Res., 76: 8021-8041.

Sykes, L.R., Kisslinger, J.B., House, L., Davies, J.N. and Jacob, K.H., 1981. Rupture zones and repeat times of great earthquakes along the Alaska-Aleutian arc, 1784-1980. In: D.W. Simpson and P.G. Richards (Editors), Earthquake Prediction, an International Review. Am. Geophys. Union, Washington DC, pp. 73-80.

Trifunac, M.D., 1971. Zero baseline correction of strong-motion accelerograms. Bull. Seismol. Soc. Am., 61: 1201-1211. 